\title{
O FINANCIAMENTO DO ENSINO SUPERIOR EM PORTUGAL: ENTRE O ESTADO E O MERCADO
}

\author{
Belmiro Gil Cabrito*
}

\begin{abstract}
RESUMO: Neste artigo discutem-se as novas tendências de financiamento do ensino superior, nomeadamente em Portugal, concluindo-se que os governos têm vindo a desresponsabilizar-se dessa sua função, apelando ao mercado e à diversificação das fontes de financiamento. Tendo em atenção que os estudantes já são os principais financiadores do ensino superior, a necessidade de se promover a equidade, bem como alguns efeitos negativos que a deserção do Estado pode acarretar para os indivíduos, para as universidades e para a sociedade em geral, conclui-se que o financiamento do ensino superior deve ser da responsabilidade do Estado, sem prejuízo da procura de outras fontes de financiamento por parte das instituições de ensino superior.
\end{abstract}

Palavras-chave: Ensino superior. Privatização. Diversificação das fontes de financiamento.

\section{Funding HigheR EDUCATION IN PORTUGAL: BETWEEN STATE AND MARKET}

ABSTRACT: This paper discusses the new trends in the funding of Higher Education in Portugal. As the State contributes less, it highlights the importance of the market and of funding diversification to guarantee Higher Education functioning. However, considering that 1) the students are already the main funding source of Higher Education, 2) more equality must be created and 3) the State desertion has negative consequences on the individuals, the institutions and the society, the author concludes that funding Higher Education is a matter of the State, even though these institutions may look for other funding sources.

Key words: Higher education. Privatization. Funding diversification.

Professor auxiliar da Faculdade de Psicologia e de Ciências da Educação da Universidade de Lisboa. E-mail: b.cabrito@fpce.ul.pt 


\section{Introdução}

7 ctualmente, qualquer membro da direcção de uma instituição do Ensino Superior Público português confronta-se, diariamente, com problemas decorrentes do desajustamento existente entre as despesas que uma instituição desta natureza precisa realizar simplesmente para poder funcionar e as disponibilidades monetárias que detém.

À semelhança de outra instituição ou serviço do Estado, o funcionamento das universidades públicas foi, até há alguns anos, totalmente assegurado pelo orçamento do Estado. Todavia, nos últimos anos, o contributo estatal para o financiamento do ensino superior diminuiu drasticamente, mesmo em termos reais. Ou seja, nos últimos anos, universidades e restantes instituiçôes públicas de ensino superior têm sido contempladas, anualmente, com uma receita inferior à que receberam no ano anterior (o valor acumulado dos cortes orçamentais, nos últimos dois anos, ascende já a $24 \%$ tomando o ano de 2002 por referência).

Poder-se-ia justificar esta situação afirmando-se que esse corte orçamental é resultante de uma diminuição das responsabilidades sociais atribuídas a essas instituições. Mas, e nisso reside a gravidade acrescida da situação, não é esse o caso. De facto:

a) Em termos globais, o número de docentes e de funcionários não-docentes não diminuiu, tal como não decresceu, ou pelo menos de forma significativa, o número de alunos (segundo dados do Departamento do Ensino Superior, 2003).

b) As expectativas do governo e da sociedade civil relativamente às instituições de ensino superior não desapareceram nem diminuíram. Na verdade, governos e empresários esperam que a universidade forme técnicos altamente qualificados e quadros superiores capazes de intervirem de forma competitiva e eficaz no mercado de trabalho. Subjacente a estas expectativas encontra-se a ideia do contributo da educação para o desenvolvimento económico, numa postura muito próxima da teoria do capital humano, "nascida" e relida com Schultz (1961, 1981) e Becker (1964, 1981), ou das novas teorias do capital humano e do crescimento económico como as propostas por Lucas (1988) e Romer (1989).

c) Em contrapartida, e segundo Cabrito (2002), os estudantes continuam a procurar no ensino superior a forma de desenvol- 
verem capacidades que lhes permitam ser mais competentes e, como tal, ofereça-lhes uma entrada mais fácil e qualificada no mercado de trabalho (numa perspectiva próxima da dos empresários). Para além disso, os estudantes procuram a universidade a fim de obter um diploma que representa um cartão de visita para o empregador (Spence, 1973; Arrow, 1973) e que se traduz num crédito capaz de os colocar, no processo de recrutamento, à frente dos indivíduos que não possuem um diploma universitário ou que possuem um diploma socialmente menos valorizado (Collins, 1979).

d) No quadro da sociedade do conhecimento e da concorrência global, a obsolescência dos saberes e do saber-fazer é contínua. Nessas circunstâncias, a formação permanente de natureza profissional surge como a resposta inevitável às exigências de "empregabilidade" que se colocam a cada indivíduo ao longo da sua vida activa. Neste sentido, o "mercado" exige das instituições de ensino superior novas ofertas educativas, que se concretizam em cursos especializados de pós-graduação, e em cursos de mestrado e de doutorado.

e) No domínio científico, as universidades e seus institutos e laboratórios associados continuam a produzir a maior parte da investigação científica (fundamental e aplicada), em face do défice da investigação a cargo dos particulares. Duas razóes fundamentais explicam essa postura dos empresários: por um lado, o retorno desse investimento também é apropriado por outros empresários numa atitude semelhante à de um passageiro clandestino (Farchy et al., 1994); por outro, porque nos encontramos ante um tecido empresarial que se caracteriza por ser constituído por uma larga maioria de pequenas e médias empresas e por um elevado número de empresários portadores de baixos níveis de escolaridade (segundo dados do Departamento de Estatística do ex-Ministério para a Qualificação e Emprego, 2003).

Desse modo, as solicitações com que a universidade se confronta não diminuíram. Pelo contrário, continua a perspectivar-se a universidade como a instituição produtora de conhecimento que permitirá ao país acompanhar o mundo desenvolvido. Ora, a estas exigências respondem os governos com cortes orçamentais. 
Em Portugal assiste-se, pois, a um fenómeno de tendência universal (Whitty et al., 1998) e que se caracteriza pela desresponsabilização do Estado em face da satisfação das necessidades colectivas, seja as de saúde, de segurança social ou de educação.

Num mundo onde todas as coisas se tornaram mercadorias, tudo o que não dá lucro imediato é abandonado. Desse modo, perante as solicitações de natureza social, diariamente aumentadas em virtude da consolidação dos regimes democráticos, os Estados, por incapacidade voluntária e/ou involuntária de encontrar mais receitas, distribuem uma pequena parcela dos seus rendimentos pelos diversos serviços sociais que, entretanto, concorrem entre si pelo financiamento público (Farchy et al., 1994).

Em Portugal, e no caso do ensino superior, ante os "protestos" das instituições universitárias, nomeadamente por meio do Conselho de Reitores das Universidades Portuguesas, respondeu o governo com a palavra mágica da governação liberal que perpassa por entre países e continentes: diversificação.

Diversificar as fontes de financiamento surge, assim, como a solução final para as dificuldades financeiras por que vêm passando as instituições públicas de ensino superior (aliás, de forma tímida, o mesmo começa a ocorrer com a educação básica e secundária).

Diversificar as fontes de financiamento surge, para as instituiçôes de ensino superior, como o último "mandamento" dos governos liberais e significa procurar fundos para além dos estatais, seja por meio da venda/prestação de serviços, da investigação "vocacionada" para o mercado ou do aumento das contribuições dos estudantes.

Ora, se é verdade que os Estados são confrontados com dificuldades para arrecadar as receitas necessárias à satisfação das necessidades colectivas (Weiler, 1999; Williams, 1999), é indesmentível a "deserção" do Estado em face da produção e provisão de bens e de serviços de natureza pública, até há pouco tempo assegurados por ele (Whitty et al., 1998). Essa deserção traduz, de facto, uma vontade política de privatização dos serviços públicos por parte de um Estado que, paulatinamente, vai abandonando a sua vocação solidária e de promoção da igualdade social, em benefício do individualismo, da concorrência e do mercado. 


\section{O Estado e o financiamento dos bens públicos}

No século passado, nomeadamente no espaço europeu, alguns serviços, pela utilidade pública de que se revestiam, eram considerados bens ou serviços públicos, cuja produção e provisão eram garantidas pelo Estado. Diversas razóes foram apresentadas para justificar esse papel "monopolista" do Estado. Entre elas destaca-se a necessidade de promover a equidade entre todos os cidadãos, característica indissociável dos regimes democráticos. Neste sentido, o Estado deveria promover a igualdade entre os cidadáos, nomeadamente por meio da garantia do acesso e da utilização de determinados bens e serviços de natureza colectiva os quais, se deixados à iniciativa privada, poderiam vir a ser colocados no mercado a um preço táo elevado que apenas alguns indivíduos teriam capacidade para os consumir (Eicher, 1998).

Naturalmente, as despesas que os Estados realizavam para produzir e prover a sociedade desses bens a preços muito baixos, ou mesmo gratuitamente, tinham retorno que, em termos económicos e sociais, justificava aqueles gastos. Isto é, a satisfação das necessidades de natureza colectiva origina externalidades que repercutem em toda a colectividade e que por ela são apropriados (Haveman et al., 1994; Weale, 1994).

No caso da educação, por exemplo, e independentemente do retorno individual que a educação traz ao seu possuidor, são muitos os efeitos sociais e colectivos dela decorrentes. Apenas para citar alguns desses efeitos, "sabe-se" que uma população mais instruída é uma população mais participativa, mais saudável, mais cumpridora da lei, mais criativa, mais autónoma etc. para além de, obviamente, mais produtiva (Wolfe, 1995).

Assim, a educação, não só constitui um factor de desenvolvimento como promove indirectamente esse desenvolvimento, em virtude dos seus efeitos externos não monetários. Desse modo, num Estado social, a produção e provisão de educação por parte do Estado encontra-se plenamente justificada (Jallade, 1998).

Todavia, desde sempre uma outra corrente teórica se apresentou em contradição com esta, pugnando pelo financiamento privado dos bens de natureza pública, em virtude de os ganhos gerados serem apropriados, maioritariamente, por cada indivíduo (Hansen et al., 1969; Arrow, 1993; Barr, 1997). Isto é, os maiores beneficiários do investimen- 
O financiamento do ensino superior em Portugal: entre o Estado e o mercado

to do Estado são os cidadãos individualmente considerados e, como tal, caber-lhes-ia financiar a produção desses bens.

Desse modo, e com maior frequência na década de 1990, muitas foram as acções dos Estados no sentido de "diversificarem" as fontes de financiamento, o que é o mesmo que responsabilizar os particulares, pelo menos parcialmente, por esse financiamento.

Naturalmente, a educação superior não fugiu a esta onda de "privatização" dos serviços públicos, e Portugal não constituiu excepção a essa tendência. De facto:

a) Perante a incapacidade do sistema educativo em responder à pressão da procura de ensino superior que o país conheceu após a Revolução Democrática de abril de 1974, tiveram continuidade diversas medidas que dificultavam a entrada na universidade dos jovens saídos do ensino secundário, por meio da fixação do número de vagas anual para cada curso e instituição (situação que ainda se mantém hoje). Ao mesmo tempo, foram criadas novas universidades públicas, dispersas pelo território nacional.

b) A partir de 1986, a produção e provisão de ensino superior foram abertas à iniciativa privada. Actualmente, cerca de um terço dos estudantes do ensino superior frequenta instituições privadas (Departamento do Ensino Superior, 2003), que praticam preços de frequência difíceis de suportar pela maior parte dos orçamentos familiares.

c) As taxas de frequência do ensino superior público cresceram, criando especiais dificuldades aos indivíduos mais desprotegidos. De um preço simbólico nos anos imediatamente a seguir à Revolução de 1974 (cerca de 6 euros por ano, entre 1974 e 1986), a taxa de frequência foi crescendo até cerca de $20 \%$ dos custos reais (atingindo cerca de 400 euros em 1993, durante a governação centro-direitista), para ser indexada ao valor do salário mínimo nacional a partir de 1994 (durante a governação socialista, atingindo cerca de 325 euros em 2002) e tornou-se variável a partir de 2003, estabelecida livremente pelas instituições de ensino superior, entre um montante mínimo de cerca de 450 euros e um valor máximo de 850 euros (de acordo 
com a nova lei de financiamento do ensino superior público, nascida da actual coligação centro-direitista no poder, sendo os valores mínimo e máximo anualmente ajustados pelo governo).

Ante esta situação de deserção do Estado, várias questôes se podem colocar e que dizem respeito quer aos indivíduos, em particular, quer à sociedade civil e ao país, em geral.

2. Alguns efeitos da "deserção" do Estado no financiamento do ensino superior

\subsection{Sobre os indivíduos}

Comecemos com as questôes respeitantes aos indivíduos: numa sociedade democrática todos os cidadãos deverão ser considerados iguais e, como tal, capacitados para o usufruto dos mesmos bens e serviços. Ora, se o financiamento do ensino superior por parte do Estado diminuir, poderá o usufruto do direito de acesso e de permanência na universidade ser afectado, criando situações de injustiça social?

Em primeiro lugar, elucide-se sobre o que são os custos do ensino superior. Seguindo autores como Johnstone (1986), Oroval et al. (1984) ou Eicher et al. (1996), os custos associados ao ensino superior ultrapassam largamente os relativos às taxas de frequência exigidas aos estudantes e às despesas necessárias para garantir o funcionamento das instituições (despesas em equipamento, em bens correntes, em pessoal). Para estes autores, a frequência da universidade implica gastos específicos por parte dos estudantes e/ou respectivas famílias, que podem ser considerados custos indirectos da educação (despesas de alojamento, de manutenção, de deslocação, de material didáctico) para além dos custos de oportunidade (representados pelos salários não ganhos pelo estudante durante o tempo de frequência da universidade).

Nessas circunstâncias, os custos do ensino superior são compostos por duas parcelas, uma a cargo do Estado e outra a cargo dos estudantes e/ou das respectivas famílias, sendo que a parte desses custos que cabe aos estudantes varia, em geral, entre os $40 \%$ e os $60 \%$ (OCDE, 1998).

No caso português, por exemplo, estudos realizados entre 19961999 com uma amostra representativa dos estudantes universitários que frequentavam a universidade, em 1995, mostram que as despesas 
O financiamento do ensino superior em Portugal: entre o Estado e o mercado

efectuadas pelos estudantes e por suas respectivas famílias (mesmo sem incluir os custos de oportunidade) excedem largamente as realizadas pelo Estado, cerca de 56\% e 44\%, respectivamente (Cabrito, 2002).

Em contrapartida, considerando que os jovens que frequentam o ensino superior são oriundos de estratos sociais diferentes, o peso das taxas de frequência sobre os orçamentos familiares é diferente, penalizando os estudantes oriundos dos estratos sociais menos favorecidos. Esse facto origina uma situação extremamente injusta, como se pode observar no Quadro 1.

\section{Quadro 1}

Peso das despesas mensais de educação nos orçamentos familiares, por classe social, dos estudantes do ensino universitário público (\%)

\begin{tabular}{|c|c|c|c|c|}
\hline Classe social & Alta & Média alta & Média & Média baixa e baixa \\
\hline Origem (\%) & 14,4 & 32,2 & 39,6 & 13,8 \\
\hline Despesas em $€(1)$ & 361,5 & 344,5 & 292,0 & 244,5 \\
\hline Orçamento em $€(2)$ & $1.855,0$ & $1.668,0$ & 838,5 & 611,5 \\
\hline Peso $(1) /(2) \times 100$ & 19,5 & 20,6 & 35,2 & 39,9 \\
\hline
\end{tabular}

Fonte: Adaptado de Cabrito, 2002.

A análise dos valores do quadro mostra que:

- uma grande parte dos jovens do ensino universitário público pertence aos estratos mais favorecidos da colectividade (46,6\%);

- o valor médio do orçamento familiar dos jovens provenientes da classe alta é o triplo do valor correspondente ao das famílias dos jovens pertencentes aos estratos mais desfavorecidos da sociedade;

- as despesas mensais efectuadas pelos estudantes diminuem à medida que caminhamos da classe alta para a classe baixa;

- o peso dessas despesas no orçamento médio dos respectivos agregados familiares é tanto mais gravoso quanto mais desfavorecido é o estrato social a que os jovens pertencem. 
A situação acima é elucidativa de um tratamento desigual da sociedade relativamente aos seus cidadãos, beneficiando aqueles que, afinal, já são os portadores de maiores níveis de capital económico e de capital cultural, dando lugar a um verdadeiro processo de reprodução das desigualdades sociais (Bowles et al., 1974; Bourdieu et al., 1970).

Este facto é agravado, ainda, por outros factores relacionados com a origem social e geográfica dos jovens. Assim, os estudantes que se encontram afastados dos grandes centros de decisão ou cujas famílias são portadoras de fracos níveis de capital cultural não só se encontram pior informados para poderem seleccionar os estudos que lhes propiciem maior nível de rendimentos e de empregabilidade como são menos sensíveis às indicações do mercado e mais permeáveis à publicidade promovida pelas instituições (Eicher, 1998).

Nestas condições, e tomando como exemplo o caso português, são altamente perniciosos o desinteresse progressivo dos Estados pelo ensino superior, bem como o processo crescente de privatização, uma vez que o aumento dos direitos de frequência das universidades públicas penaliza os jovens de mais baixos rendimentos; e, no caso das universidades privadas, o valor das mensalidades é tão elevado que tende a afastar os jovens com piores condições económicas.

Numa situação como a portuguesa, em que o número de vagas das universidades públicas é limitado, este processo é duplamente penalizador para os jovens dos estratos sociais mais desfavorecidos porque, ante os preços que as universidades privadas praticam, têm de tentar o acesso a uma universidade pública. Ora, se aceitarmos que a escola reproduz as desigualdades sociais (Baudelot et al., 1977; Bernstein, 1996), os jovens oriundos de estratos sociais portadores de menores níveis de capital económico e cultural têm mais insucesso escolar e, em consequência, menos hipóteses de entrar nas universidades públicas, cujo acesso depende da classificação obtida no ensino secundário e nos exames específicos para $\mathrm{o}$ acesso à universidade.

Obviamente, tendo em conta os preços das universidades privadas, esses jovens são discriminados negativamente pela sociedade portuguesa. Nessas circunstâncias, falar-se em "partilha de custos" em face da deserção progressiva do Estado relativamente ao financiamento das universidades públicas, exortando-as a procurar outras fontes de financiamento, as quais se concretizam, na maior parte das vezes, no aumen- 
O financiamento do ensino superior em Portugal: entre o Estado e o mercado

to das taxas de frequência, é, de facto, discriminar cidadãos e contribuir para perpetuar as injustiças e as desigualdades sociais.

\subsection{Sobre a sociedade}

Do ponto de vista social, que dizer? A realidade não parece melhor. De facto, e apesar de sabermos hoje que a relação que se estabelece entre a educação e a produtividade não é nem tão linear nem tão estreita quanto o afirmado pelos teóricos do capital humano (Psacharopoulos et al., 1985; Levin, 1995), a verdade é que todas as correntes teóricas que se preocupam com a relação existente entre a educação e o trabalho concedem à educação um papel essencial (a par de outros factores) não só no desenvolvimento económico, social e cultural de um país ou região mas também no desenvolvimento pessoal dos indivíduos e das suas relaçôes com os demais.

$\mathrm{Na}$ verdade, se uma população mais educada não é, necessariamente, mais produtiva, é incontroverso o facto de que a educação é um factor determinante dessa produtividade. Por um lado, na escola os indivíduos desenvolvem capacidades que lhes permitem uma socialização antecipada no mercado de trabalho e tornam mais fácil e económica essa inserção (Shilling, 1989). Por outro lado, as capacidades de decisão, de trabalho em equipa, de autonomia, de organização, de liderança, entre outras, são capacidades que os indivíduos desenvolvem durante o tempo que passam na escola e que favorecem as relações que estabelecem no mercado de trabalho com as chefias, com os seus pares, com os seus subordinados e mesmo com o equipamento.

Nessas condições, qualquer política restritiva do consumo de educação, nomeadamente de grau superior, faz perigar o desenvolvimento que se pretende para os países e as populações, mesmo que se aceite, como refere Fuller (1992), que as taxas de retorno individual do ensino superior são mais elevadas do que as taxas de retorno de natureza social.

Para além disso, a educação permanente, uma boa parte dela levada a cabo pelos estabelecimentos de ensino superior, favorece processos de autoformação e de actualização e reciclagem profissionais indispensáveis à adaptação de cada indivíduo às inovações e mudanças que caracterizam a sociedade actual. 
Desse modo, a deserção do Estado ante o ensino superior, concretizada em processos de privatização e de desresponsabilização no financiamento da sua produção, deixando ao "mercado educativo" (Weiler, 1999) a responsabilidade da produção e distribuição do ensino, é uma medida política questionável, quer em termos de justiça social quer em termos "meramente" económicos e financeiros.

Em contrapartida, com a educação não só se transmitem conhecimentos, se aprendem saberes e se desenvolvem capacidades e competências, como se assegura a permanência dos valores sociais, se garante a coesão social, se sensibiliza para as questões ambientais e se apela à melhoria da qualidade de vida (Levin, 2003). Em consequência, qualquer medida de política educativa que dificulte o acesso dos cidadãos à educação estará a dificultar um processo de criação de uma sociedade mais justa e equitativa e, portanto, terá efeitos negativos em termos sociais.

\section{A acção do Estado: razões e soluções}

Para justificar o processo de privatização encetado, os governos, nomeadamente o português, apresentam diversos argumentos. Assim, e sem pretender ser exaustivo:

- uma vez que o maior beneficiário do ensino superior é o aluno, isto é, a taxa de retorno individual é superior à taxa de retorno social do investimento educativo, então o aluno deverá pagar pelo serviço obtido, numa lógica de "utilizador-pagador";

- tendo de pagar pela sua educação, o estudante torna-se mais responsável, pelo que terminará os seus estudos mais depressa para poder vir a ter, mais cedo, o retorno do investimento que efectuou;

- tornando-se um financiador das instituições, o estudante tem maior controlo sobre o sistema, podendo exigir um ensino de melhor qualidade;

- se o Estado continuar a financiar o ensino superior, toda a colectividade estará a ser um financiador activo, mesmo aqueles indivíduos cujos rendimentos não permitem que os seus filhos possam vir a frequentar a universidade; 
O financiamento do ensino superior em Portugal: entre o Estado e o mercado

- a abertura à iniciativa privada enquadra-se numa política de liberdade de escolha, inviável de praticar sempre que o Estado seja o único fornecedor do serviço;

- a promoção da concorrência entre os estabelecimentos públicos, e entre eles e os estabelecimentos privados numa situação próxima de um quase-mercado (na acepção de Le Grand, 1996), garante um melhor serviço educativo com menores custos;

- a existência de competição entre os estabelecimentos conduzirá ao aparecimento de padróes de excelência, que repercutirão na qualidade do ensino dos diversos estabelecimentos.

Além disso, e no sentido de criar a necessária equidade e possibilitar o exercício do direito de escolha, os governos, sobretudo o português, propõem diversas medidas para solucionar o problema da equidade e justiça social, nomeadamente:

- estabelecer políticas de apoio social específicas, para os estudantes com maiores dificuldades financeiras, a fim de lhes garantir o acesso ao ensino superior;

- estabelecer condições que facilitem o deslocamento dos estudantes para regióes afastadas do seu ambiente usual, quando não conseguem o acesso a uma instituição de ensino superior na região de habitação permanente;

- criar linhas de crédito bonificado, de forma que nenhum jovem possa ser impedido de frequentar o ensino superior por razões de natureza económica;

- atribuir cheques de ensino (vouchers) a todos os jovens, a fim de lhes permitir escolher o estabelecimento de ensino que desejarem.

\section{Das promessas à realidade: o caso português}

No quadro dos argumentos apresentados, quase parecem aceitáveis as novas soluções propostas pelos governos e que passam pela privatização parcial do serviço público educativo, em dois níveis: por um lado, por meio da participação dos estudantes no financiamento das uni- 
versidades públicas; por outro, pela abertura do "mercado" do ensino superior à iniciativa privada.

Todavia, a experiência tem mostrado que essas medidas não se saldam em equidade e justiça social, podendo, pelo contrário, agravar as desigualdades sociais, com evidentes efeitos indesejáveis.

Efectivamente, e o exemplo português não será, obviamente, caso único; as "políticas de apoio especial específicas" não têm conduzido à equidade desejável e "prometida" antes se saldando, em geral, por rotundos fracassos. Na verdade, essas políticas de apoio "dirigidas", nomeadamente a isenção do pagamento das taxas de frequência com a atribuição (ou não) de bolsas de estudo, têm vindo a assumir uma natureza altamente discriminatória.

Efectivamente, a lista dos estudantes “isentos" e dos estudantes "bolseiros", se, por um lado, garante transparência de processos, por outro, invade a privacidade de cada estudante. De registar é que a própria figura de "isenção" veio a ser abolida ainda nos últimos anos da década de 1990, exactamente por essa razão.

Para além disso, segundo valores do Departamento do Ensino Superior (2003), o valor máximo da bolsa atribuída (aproximadamente igual a um salário mínimo) atinge menos de $1 \%$ dos estudantes universitários. Ora, mesmo nesses casos (em que o estudante tem de ser, realmente, muito carenciado), o valor da bolsa não cobre as despesas associadas à educação.

Além disso, uma relação social injusta raramente se resolve a montante do problema que lhe deu origem. Ora, a "pobreza" de inúmeros estudantes em Portugal dificilmente se ultrapassa sem se combater o problema na origem, e que não é mais do que o resultado de uma distribuição injusta e assimétrica do rendimento nacional e de políticas fiscais de redistribuição do rendimento geradoras de desigualdades sociais.

No que respeita aos estudantes deslocados, os apoios "específicos" referidos "reduzem-se" a algumas "residências" onde os estudantes podem morar, a preços módicos. O problema é que, segundo informações do Conselho Nacional de Acção Social Escolar (CNASE, 2003), o número de "camas" disponível não responde a mais de $10 \%$ das necessidades. 
Por seu turno, "a liberdade de ensinar e de aprender" nem é garantida pela existência de escolas privadas nem é impedida pelo facto de o ensino superior ser, apenas, de natureza pública.

A existência de instituições de natureza privada, praticando mensalidades mais caras porque se tratam de verdadeiras empresas, dificilmente poderia contribuir para a "liberdade de escolha", dado que o respectivo preço impede que uma boa parte dos jovens se possa candidatar a elas. Para obviar este inconveniente, os governos propõem uma política de apoio financeiro concretizado no cheque de ensino (voucher). A cada estudante seria atribuído um cheque de ensino, que ele utilizaria para pagar a mensalidade da instituição que desejasse, pública ou privada.

Naturalmente, essa medida teria êxito se o montante do voucher variasse de acordo com a escola a que o estudante se candidatasse. Ora, uma vez que o valor do voucher é igual para todos os estudantes, independentemente do nível de rendimentos do seu agregado familiar e da instituição de ensino superior que se pretende frequentar, esta é uma falsa medida de construção da equidade, dado que a candidatura do estudante a cada instituição se encontra dependente dos recursos financeiros de que pode dispor, para além do cheque de ensino.

Em contrapartida, argumentar com a "mercantilização" do ensino superior para garantir o direito de escolha e de opção sobre "o que se quer ensinar e aprender" (Barr, 1993; Williams, 1995) é ignorar que, no quadro da autonomia de que gozam os estabelecimentos de ensino superior, cada instituição pode desenvolver o "ensino" em "liberdade", pois são os seus conselhos científicos que avalizam cursos, currículos, metodologias de trabalho e processos de avaliação, e que fazem (ou deveriam fazer) a necessária articulação entre as ofertas educativas, as necessidades individuais e as necessidades do mercado.

Finalmente, a prática tem vindo a mostrar a ineficiência das políticas de crédito como forma de garantir a todos os indivíduos, em especial aos economicamente mais carenciados, a possibilidade de frequentar o ensino superior. Efectivamente, a experiência tem mostrado que essas políticas beneficiam fundamentalmente os estudantes oriundos de estratos sócio-económicos privilegiados. Quer dizer, são os jovens sem problemas monetários aqueles que vão aproveitar as políticas de crédito bonificado, pois não receiam endividar-se, dado que contam sempre com o apoio da família perante qualquer problema financeiro. 
Pelo contrário, os jovens com menos recursos têm "aversão" ao endividamento pois, não sabendo quando se empregarão e qual o rendimento de que irão dispor, têm receio de não conseguirem pagar o empréstimo. No caso português a situação é absolutamente paradigmática. Dê-se atenção ao Quadro 2:

\section{Quadro 2}

Distribuição dos pedidos de empréstimo para apoio aos estudos, por classe social $(\mathrm{em} \%)$

\begin{tabular}{|c|c|c|c|c|}
\hline Classe social & Alta & Média alta & Média & Média baixa e baixa \\
\hline $\begin{array}{c}\text { Pedidos de } \\
\text { empréstimo }\end{array}$ & 33,3 & 34,6 & 21,8 & 10,2 \\
\hline
\end{tabular}

Fonte: adaptado de Cabrito, 2002.

A análise dos valores do quadro é bem elucidativa: cerca de $68 \%$ dos estudantes que aproveitaram empréstimos bonificados para as despesas inerentes à sua educação, em Portugal, em 1995, pertenciam às classes alta e média alta. Mesmo que aceitemos que, entre essa data e hoje, possa ter havido alguma mudança nas atitudes individuais, creio que a situação actual não será muito diferente.

Aliás, as políticas de trabalho aplicadas pelo governo nos dois/ três últimos anos, que conduziram à liberalização dos contratos de trabalho e ao aparecimento do trabalho precário, associadas ao desemprego crescente dos diplomados do ensino superior, podem ter tido, como consequência, uma maior recusa de endividamento por parte dos estudantes mais pobres.

\section{Reflexões finais}

Em face do exposto, dificilmente se poderá acreditar nas virtudes do "mercado" e das iniciativas dos governos neo-liberais, para criar equidade, quando as condiçóes de partida de cada jovem candidato a estudante do ensino superior são tão diferentes e as medidas de natureza "social" propostas assentam na competição e em valores que promovem o individualismo. 
A experiência vem mostrando, então, que a abertura do mercado do ensino superior à iniciativa privada não elevou os níveis de equidade, antes promoveu a concorrência entre pares e criou novas dificuldades para frequentar a universidade.

Além disso, a deserção do Estado ante o ensino superior, abdicando de uma prática que, até há bem pouco tempo, era da sua responsabilidade, tem vindo a contribuir para a concorrência entre instituições, por alunos, professores e financiamentos ao mesmo tempo que dificulta o acesso de alguns indivíduos à educação.

Para além disso, as propostas neo-liberais de privatização do ensino superior vêm negar o "direito" de todos à educação, ao fazer o seu usufruto depender da riqueza de cada estudante, isto é, da capacidade financeira de que cada um é portador, a fim de comprar este serviço.

Isto é, no quadro da produção e distribuição de ensino superior, o mercado (mesmo que suavizado na formulação dos quase-mercados) tende a agravar situações, cria maiores desigualdades sociais e injustiças e tem efeitos negativos no número de jovens a frequentar o ensino superior, com as naturais consequências na colectividade, seja no nível da produção e da produtividade, seja no nível do gozo de um direito de cidadania plena.

Neste sentido, creio que este grau de ensino, à semelhança do que acontece ainda numa boa parte do Continente Europeu, deveria continuar a ser financiado e provido pelo Estado, colocado à disposição gratuitamente a todos os estudantes que para tal mostrassem capacidade e apoiado noutras políticas sociais, nomeadamente na atribuição de bolsas para as despesas de manutenção e na promoção de políticas de crédito bonificado, como o imposto sobre o rendimento proposto por Barr et al. (1998).

A equidade e a justiça social, bem como o desenvolvimento económico, exigem, assim, que se continue a apostar na "escola pública", devendo os governos, para obterem os recursos necessários, intervir em sede própria: o sistema fiscal. $\mathrm{Na}$ verdade, qualquer esforço que se possa realizar no sentido da promoção da equidade e do desenvolvimento terá que assentar num sistema fiscal justo, que assente, fundamentalmente, nos impostos directos, que trate de forma diferente rendimentos diferentes e que não permita a evasão fiscal.

Naturalmente, o facto de o Estado garantir o funcionamento das universidades não desvaloriza quaisquer iniciativas das instituições de 
ensino superior para conseguir mais financiamento, nomeadamente por meio da investigação aplicada, da prestação de serviços de consultoria à comunidade ou na procura de mecenato. Ou seja, o problema não se encontra na diversificação das fontes de financiamento (se delas exceptuarmos os estudantes). O problema reside na imposição dessa diversificação por meio de orçamentos deficitários, criando situações de dependência em face do mercado que podem pôr em risco a autonomia da universidade ou mesmo a sua sobrevivência (Barnes, 1999).

Recebido e aprovado em setembro de 2004.

Referências bibliográficas

ARROW, K. Higher education as a filter. Journal of Public Economics, Amsterdam, v. 2, n. 3, p. 193-216, 1973.

ARROW, K. Excellence and equity in higher education. Education Economics, Oxfordshire, v. 1, n. 1, p. 5-12, 1993.

BARNES, J. Funding and university autonomy. In: Henkel, M.; LitTle, B. (Ed.). Changing relationships between higher education and the State. London: Jessica Kingsley Publishers, 1999. p. 162-190.

BARR, N. The economics of the welfare state. London: Weidenfeld \& Nicolson, 1993.

BARR, N. Student loans: towards a new public/private mix. Public Money and Management, Oxford, v. 17, n. 3, p. 31-40, 1997.

BARR, N.; CRAWFORD, I. Funding higher education in an age of expansion. Education Economics, Oxfordshire, v. 6, n. 1, p. 45-70, abr. 1998.

BAUDELOT, C.; ESTABLET, R. L'école primaire divise. Paris: Maspero, 1977.

BECKER, G. Human capital: a theoretical and empirical analysis, with special reference to education. New York: Columbia University, 1964.

BECKER, G. A treatise on family. Cambridge, Mass.: Harvard University, 1981. 
O financiamento do ensino superior em Portugal: entre o Estado e o mercado

BERNSTEIN, B. Pedagogy, symbolic control and identity: theory, research, critique. London: Taylor \& Francis, 1996.

BOURDIEU, P.; PASSERON, J.-C. La reproduction. Paris: Minuit, 1970 .

BOWLES, S.; GINTIS, H. Schooling in capitalist America: educational reform and the contradictions of economic life. New York: Basic Books, 1974 .

CABRITO, B. O financiamento do ensino superior universitário, em Portugal. Lisboa: Educa, 2002.

COLLINS, R. The credential society: a historical sociology of education and stratification. New York: Academic, 1979.

EICHER, J.-C. The costs and financing of higher education in Europe. European Journal of Education, Dorchester-on-Thames, v. 33, n. 1, p. 3139, mar. 1998.

EICHER, J.-C.; GRUEL, L. Le financement de la vie étudiante. Paris: La Documentation Française, 1996.

FARCHY; J.; SAGOT-DUVAUROUX, D. L'économie des politiques culturelles. Paris: PUF, 1994.

FULLER, B. Educational expansion and economic growth. In: FulLER, B.; Rubinson, R. (ed.). The political construction of education. New York: Praeger, 1992. p. 101-116.

HANSEN W.; WEISBROD, B. The distribution of costs and direct benefits of public higher education: the case of California. Journal of Human Resources, Madison, v. 4, p. 176-191, 1969.

HAVEMAN, R.; WOLFE, B. Schooling and the economic weel-being: the role of nonmarket effects. In: CoHn, E.; Johnes, G. (Ed.). Recent developments in the economics of education. Aldershot: Edward Elgar, 1994. p. 153-183.

JALLADE, J.-P. Le financement des universités européennes: tendances recentes. Paris: Institut Européen d'Éducation et de Politique Sociale, 1998.

JOHNSTONE, D. Sharing the costs of higher education. New York: College Entrance Examination Board, 1986. 
LE GRAND, J. Los cuasi mercados y la política social. In: Oroval, E. (Ed.). Economia de la educación. Barcelona: Ariel Educación, 1996. p. 257-271. (Trad. de Economic Journal, v. 101, p. 1256-67, 1991)

LEVIN, H. Work and education. In: CARNOY, M. (Ed.). International encyclopedia of economics of education. 2. ed. Cambridge, Mass.: Pergamon, 1995. p. 10-19.

LEVIN, H. Os "cheques-ensino": um quadro global de referência para a sua avaliação. In: BARroso, J. (Org.). A escola pública: regulação, desregulação, privatização. Porto: ASA, 2003. p. 111-148.

LUCAS, R. On the mechanisms of economic development. Journal of Monetary Economics, Amsterdam, v. 22, p. 3-42, 1988.

ORGANISATION FOR ECONOMIC CO-OPERATION AND DEVELOPMENT (OCDE). Education policy analysis. Paris: Centre for Educational Research and Innovation, 1998.

OROVAL. E.; MOLTO GARCIA, T. Costes y rendimientos en la enseñanza superior. Barcelona: Universitat de Barcelona; Institut de Ciências de l'Educacion, 1984.

PSACHAROPOULOS, G.; WOODHALL, M. Education for development: an analysis of investment choices. New York; Oxford: Oxford University, 1985.

ROMER, P. Human capital and growth: theory and evidence. Cambridge, Mass.: National Bureau of Economic Research, 1989. (Working paper n. 3173)

SCHULTZ, T. Investment in human capital. American Economic Review, Nashville, v. 51, p. 1-16, 1961.

SCHULTZ, T. Investing in people: the economics of population quality. Berkeley: University of California, 1981.

SHILLING, C. Schooling for work in capitalist Britain. London: Falmer, 1989.

SPENCE, M. Job market signalling. Quarterly Journal of Economics, Cambridge, Mass., v. 87, n. 3, p. 335-374, 1973. 
O financiamento do ensino superior em Portugal: entre o Estado e o mercado

WEALE, M. Externalities from education. In: CoHn, E.; JoHnes, G. (Ed.). Recent developments in the economics of education. Aldershot: Edward Elgar, 1994. p. 115-138.

WEILER, H. Universities, markets, and the State: higher education financing as a laboratory of change. CESE Newsletter, 41, may 1999. p. $19-25$.

WHITTY, G.; POWER, S.; HALPIN, D. Devolution and choice in education: the school, the State and the market. Buckingham: Open University, 1998.

WILLIAMS, G. The "marketization" of higher education: reforms and potential reforms in higher education finance. In: Dill, D.; SpORN, B. (Ed.). Emerging patterns of social demand and university reform: through a glass darkly. Oxford: Pergamon, 1995. p. 170-193.

WILLIAMS, G. State finance of higher education: an overview of theoretical and empirical issues. In: Henkel, M.; Little, B. (Ed.). Changing relationships between higher education and the State. London: Jessica Kingsley, 1999. p. 142-161.

WOLFE, B. External benefits of education. In: Carnoy, M. (Ed.). International encyclopedia of economic 